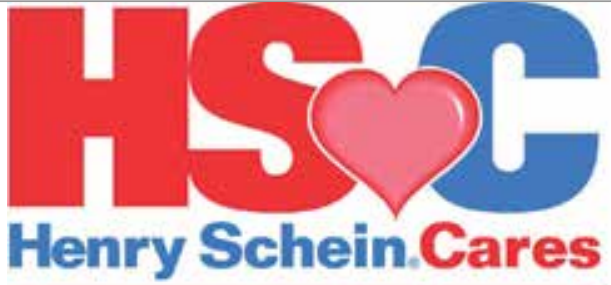

Helping Health Happen.

\title{
Spende
}

\section{Über 1 Mio. US-Dollar für den Kampf gegen die Ebola-Epidemie}

Henry Schein Inc. gibt bekannt, dass das Unternehmen und seine Industriepartner persönliche Schutzausrüstung (PSA) im Wert von über 1 Mio. US-Dollar spenden, um sich aktiv gegen die Ausbreitung der Ebola-Epidemie einzusetzen. Das Unternehmen arbeitet hierbei eng mit der CDCFoundation (Zentren für Krankheitskontrolle und Prävention) und anderen Hilfsorganisationen zusammen, darunter AmeriCares, Direct Relief, International Medical Corps und MedShare, um den Bedarf an medizinischen Hilfsgütern kontinuierlich zu überprüfen und den Ausbruch von Ebola in Westafrika zu bekämpfen. Henry Schein spendet Gesichtsmasken, Schutzhandschuhe und Kittel sowie Handdesinfektionsmittel, Schutzanzüge und andere Schutzausrüstung.

Davon erhält die CDC-Foundation Hilfsgüter im Wert von 500000 US-Dollar. Der restliche Betrag geht an Henry Scheins strategische, nichtstaatliche Partner-Organisationen (NGO), unter anderem die oben genannten. Auch die Lieferpartner von Henry Schein, einschließlich Crosstex International, Inc., KaVo Kerr Group, Medicom LLC und PDI Healthcare, unterstützen die Hilfsaktion des Unternehmens im Kampf gegen den Ebola-Ausbruch. Die eingeleitete Notfallhilfe spiegelt einen wesentlichen Aspekt von Henry Schein Cares wieder. Um die Einsatzfähigkeit bei Notfällen in aller Welt zu beschleunigen, liefert Henry Schein Cares regelmäßig Produkte an internationale Hilfsorganisationen, um deren Läger im Falle einer Katastrophe gut aufzustellen.

Zusätzlich hat die Henry Schein CaresFoundation zur Bekämpfung des Virus einen Ebola-Hilfsfonds in den USA eingerichtet. Diese gemeinnützige Stiftung unterstützt und fördert den weltweiten $\mathrm{Zu}$ gang zur gesundheitlichen Versorgung.

Nach einer Pressemitteilung der Henry Schein Dental Deutschland GmbH,

Langen 